\title{
Proceedings
}

\section{Design and Validation of Cable Forestry Operation by 3D Modeling/ Simulation - Standardize, Rigging Up and Database of Operations - +}

\author{
Toshio Nitami ${ }^{1}$ \\ 1 Assoc. Prof. Dr., The University of Tokyo ; nitami@fr.a.u-tokyo.ac.jp \\ + Presented at the 1st International Electronic Conference on Forests, 15-30 November 2020; \\ Available online: https://sciforum.net/conference/IECF2020
}

Published: 15 November 2020

\begin{abstract}
Cable skyline systems are often used to yard felled trees in mountain forests. As they are in the difficult terrain forest stands and these operations are process of the works by temporal setting at the irregular shape site, it has been difficult to be standardized and to store results useful for the following operations. Pre-processes for the operation are inevitable such as for design of process management and for mechanism rig up of the operation and usually their simplification is expected, and always the craftsmanship of the operation staff is required. The recent development of highdefinition local environmental information and the ease of public use made it easy for them to be made possible in a short period of time. Furthermore, the simulation method using CG technology makes it possible to examine various location relationship, mechanisms, etc. of real threedimensional space by VR etc. Here I show 1) modeling the main rigging method that has been used so far in a digital three-dimensional space on a PC, 2) cable rigging can be designed quickly, one day for a yarding site, 3) validating and revising smooth yarding operation, by virtual yarding operation with keyboard/joystick control for design better setting and operation, 4) designing and creation of data system for storing the results of the operation to improve following operations, which may support timber SCM. Moreover, it can be applied to develop a new cable skyline mechanism.
\end{abstract}

Keywords: forest; cable; yarding; VR; simulation; 3D; harvesting; terrain; technique; standardize

\section{Introduction - Skyline Cable Operation and Requirements Today}

Timber production operation in forestry is not easy to perform efficiently in mountainous forest countries. Cable skyline yarding systems have been developed and used in many countries and regions. The design of cable skyline system and appropriate mechanism is used according to the operating field conditions. Vehicle based cable machinery came to utilized globally but conventional yarding cables are still installed for the operation. These fields are vast and terrain difficult to compile and store the operation result useful along with standardize the equipped mechanisms/alignment. Here introduced a virtual three-dimensional information space to model such cable skyline system. The cable skyline system over placed on mountainous terrain enables us to discuss the suitable location cable alignment. It also enables us to figure the method and technique by digital model. And, which makes possible to transform/inherit them and skill for them to others and successors.

\section{Material, Solution and Sequence}

We follow sequence of processes for bunch of work here.

Preparation - field and business condition 
The operation field conditions are to take into design consideration, such as final or thinning, location, area, boundary, tree species, age and volume and so on.

- Terrain and Skyline load - Ground clearance

We import digital ground height information onto map and discuss location of spar tree for head and tail mast of skyline cable in consideration for the cable and ground clearance and yarding efficiency by lateral yarding from the center skyline.

- Cable safety and Rigging layout

Skyline cable wire is designed suit for rigging at strength safety. Operating lines are adequately layout for operation.

- Operation simulation

Operation is simulated at several timber harvesting location. It provides us estimations for yarding cycle-time. After conducting yarding over the harvesting site, we discuss and adjust alignment for operation line and guide block locations.

\section{Digitize Operation Site and Surrounding}

Terrain data acquisition for 3D modeling utilize national land information database when without aerial LiDAR data, which would be utilized if available.

We design cable skyline system replicate the field yarding operation. A large clear-cutting area conducted by a large cable skyline system is shown on Figure 1 (Google Earth) is utilized for the discussion here and the digital height map is cut out from national land information database which has $5 \mathrm{~m}$ resolution.

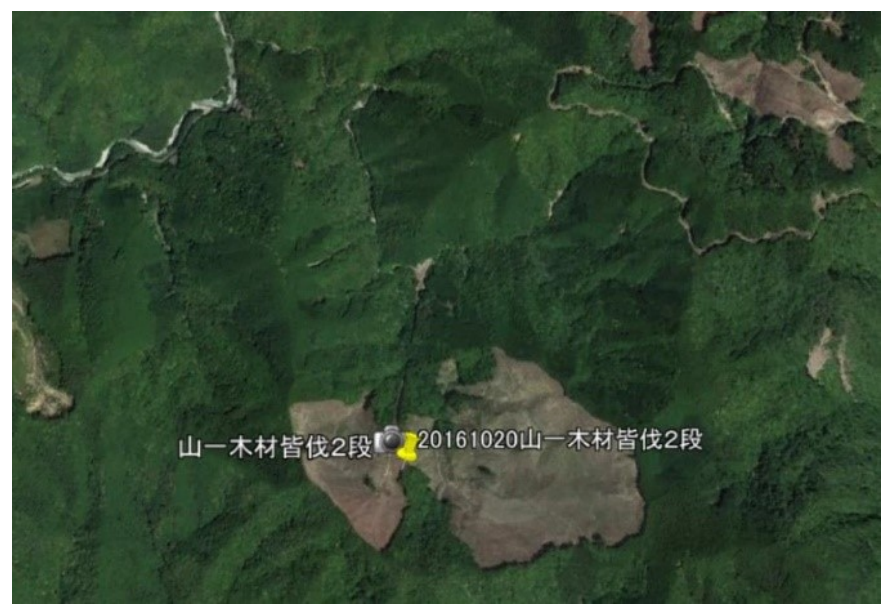

Figure 1 Operation site for clear cut.

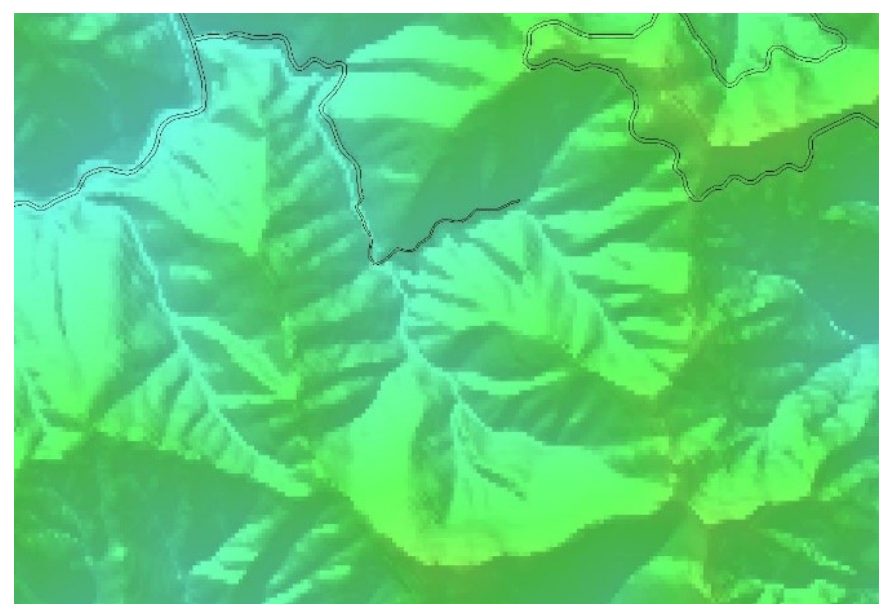

Figure 2 Cut out area on digital map. 


\section{3Dimensional Terrain Mode}

3Dimensional terrain model is created by Digital Hight Map through converting to grayscale data 2), Figure 3, onto the Unity model space, Figure 4.

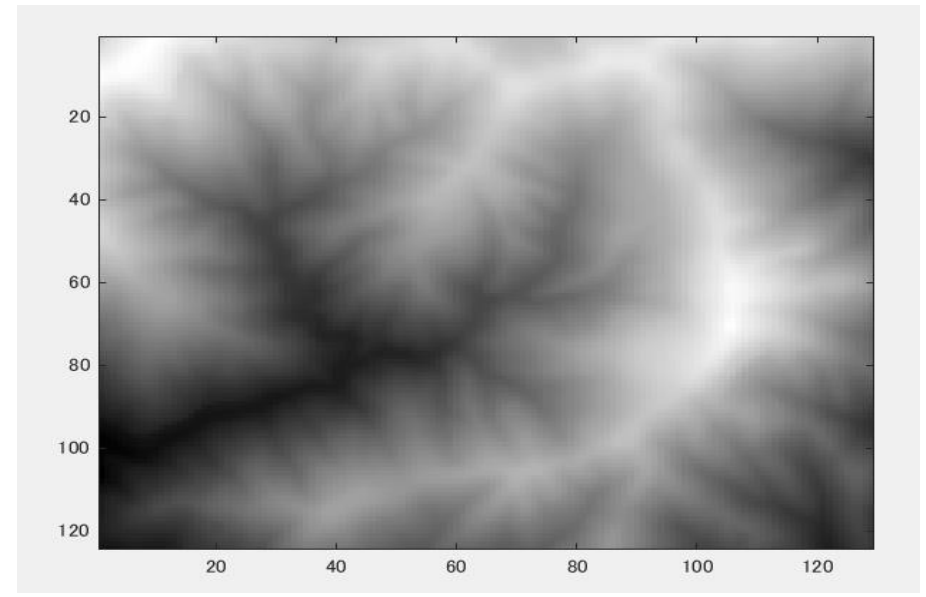

Figure 3. Grayscale digital height map.

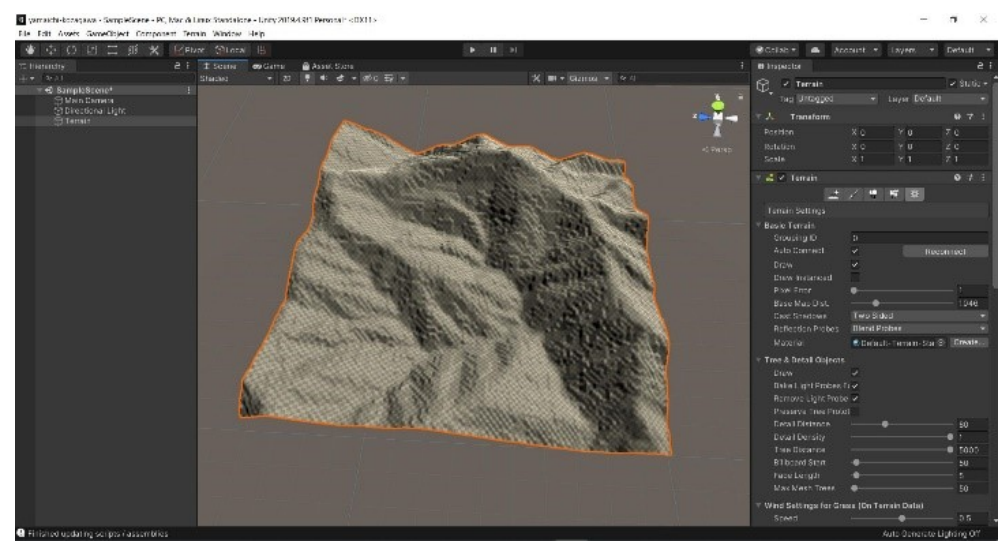

Figure 4. 3D terrain model in Unity space.

\section{Location and Safety Evaluation}

Digital height map is imported to Matlab to discuss head/tail spar tree location and terrain ground clearance, Figure 5.

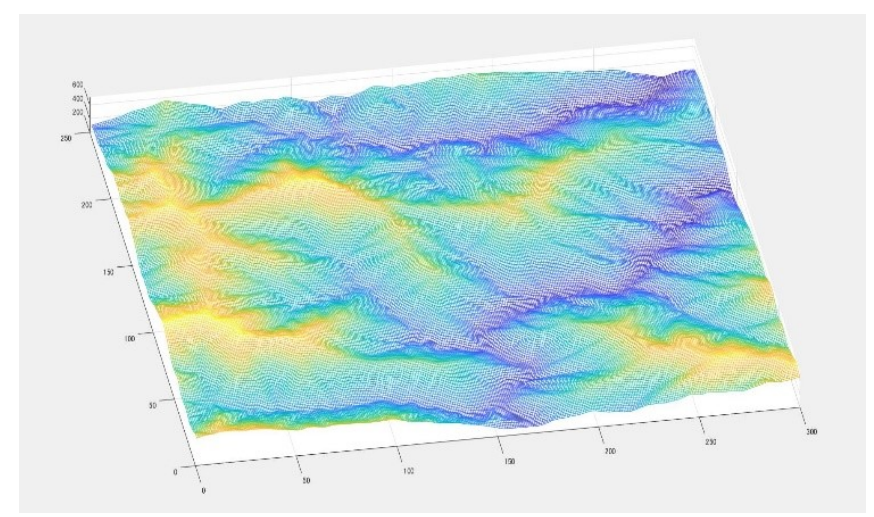

Figure 5. Matlab DHM display for discussion. 


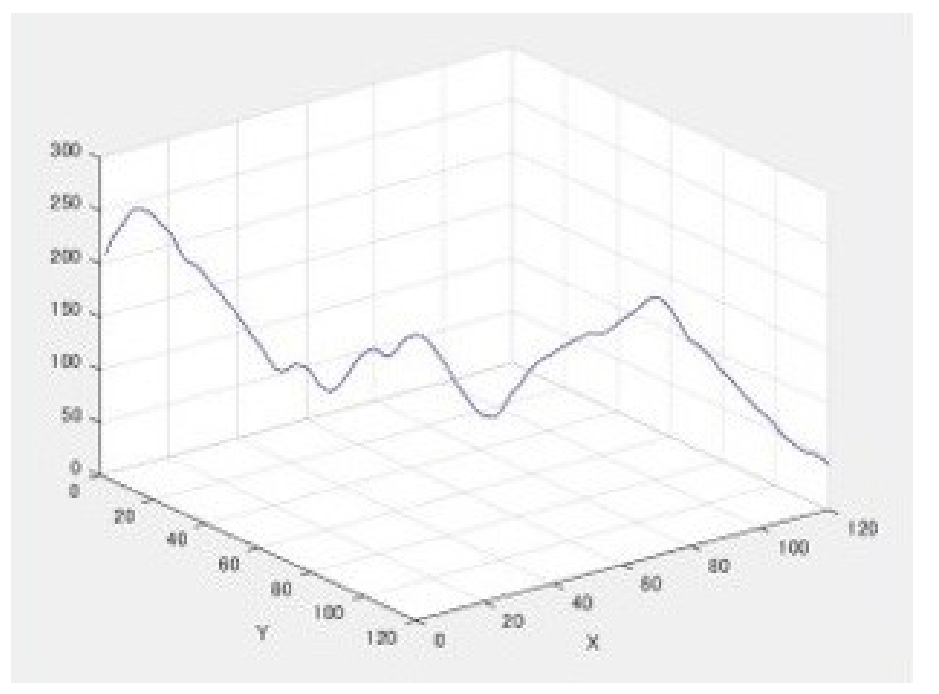

Figure 6. Terrain profile discussion.

Terrain surface profile, Figure 6, is imported to a cable design package for feasible rigging with cable brake safety and promote operational efficiency. A set of Excel sheets for cable skyline safety design was introduced and evaluate the cable alignment and wire design. Terrain surface profile is calculated along planned skyline and see ground contact when loaded.

Skyline cable safety for wire rope breakage is also discussed here. A skyline sag-span ratio and cable wire thickness are adjusted to have enough wire rope strength for operation concern national standard. But simulation tool for 3D cable design has no function relating to wire material/structure and property, such as extension, weight and thickness. And we applied parabolic skyline cable theory 4). Figure 7 shows a skyline design and the sagging shape along cable line, which has 0.04 for sagspan ratio and $24 \mathrm{~mm}$ for cable wire thick. Design operation load is $1 \mathrm{t}$. You see $530 \mathrm{~m}$ for span between head and tail pier tree, $10 \mathrm{~m}$ for pier tree height at the skyline block. Bird eye view of the cable installation is as on Figure 10.

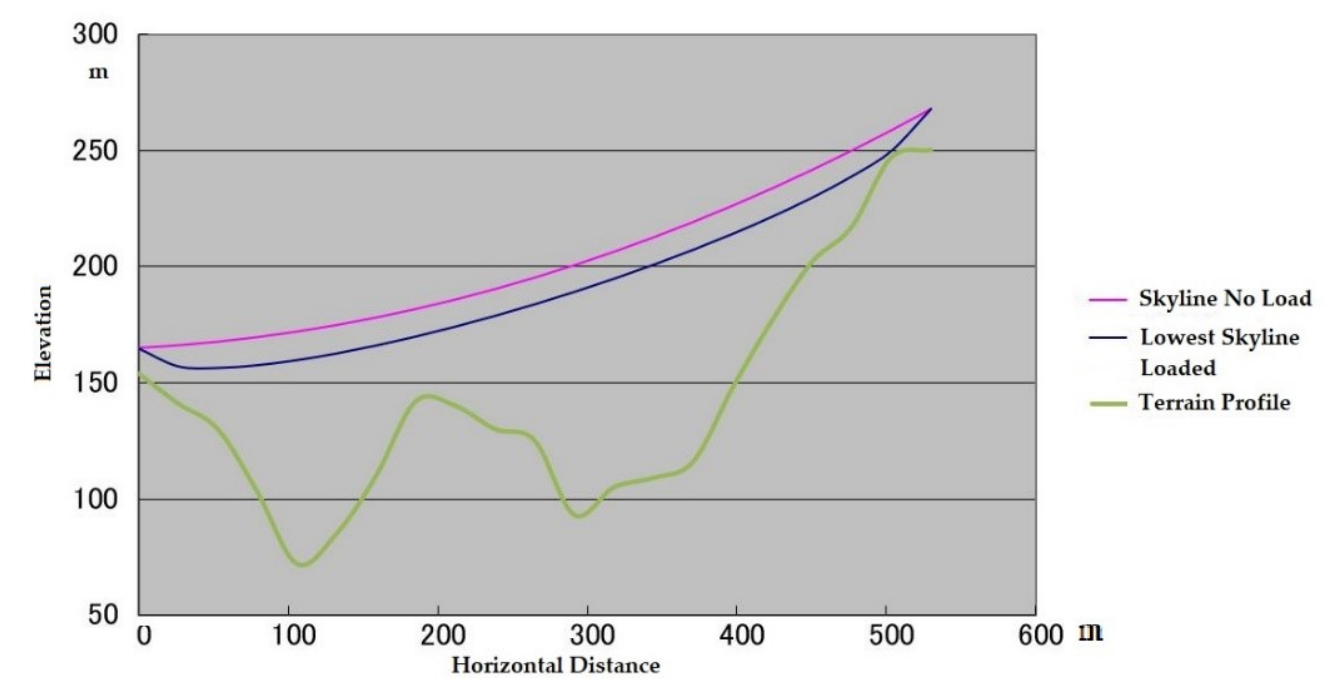

Figure 7. Skyline and Terrain profile.

\section{Create Database of Cable Skyline Systems}

Designs of cable skyline systems are packed to make a database. Cable system, such as Endless Tyler, Double Endless are standard structure as on Figure 8 and 9. Tower Yarder can be involved by 
adding vehicle to cable system. We use this modeling under VR technology to visualize and discuss possibility for construction a cable skyline system so far.

This enables easy setting by transporting and superimposing the cable mechanisms onto the field Digital Hight Model.

Cable skyline mechanisms are modeled by wire cable simulation asset Filo. We put yarding cable system construction parts though Unity elements and add pully/drum and wire through Filo elements.

As usual at Unity, we need make some parts connected to other and move around joint on it, which typically inevitable to design skyline carriage. Drums to activate operation lines need to be installed with motor function and they come with action control scripts which enable keyboard type commands to activate drums to rotate. We used drum winding speed $6 \mathrm{~m} / \mathrm{sec}$, which is usual in forestry yarding operation, to resembles it moves with reality. Drum action control is expected to maneuver run at variety speed for condition requires.

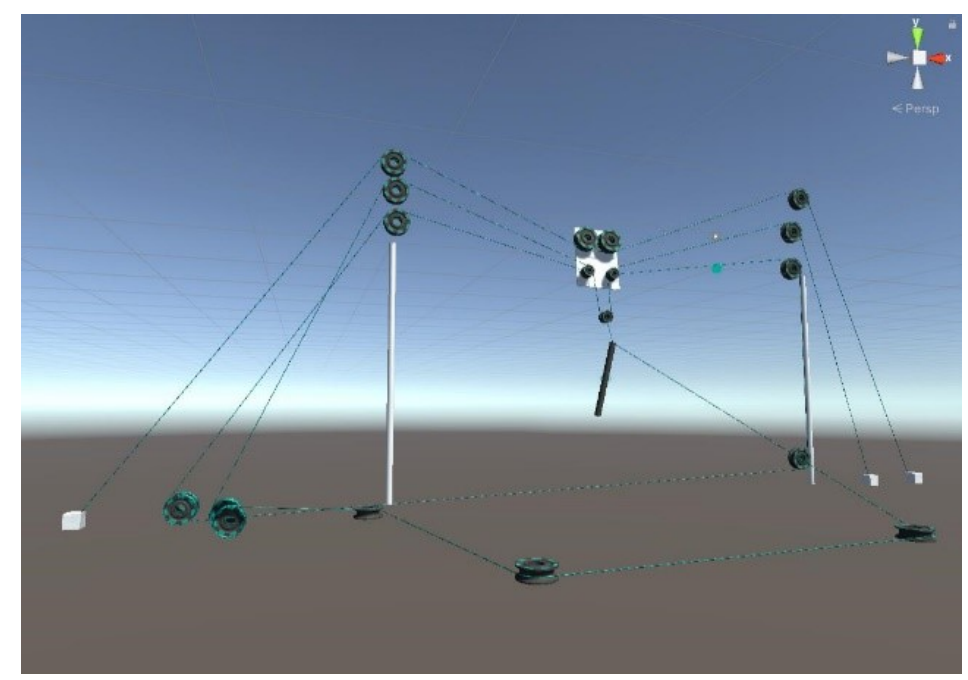

Figure 8. Endless Tyler system.

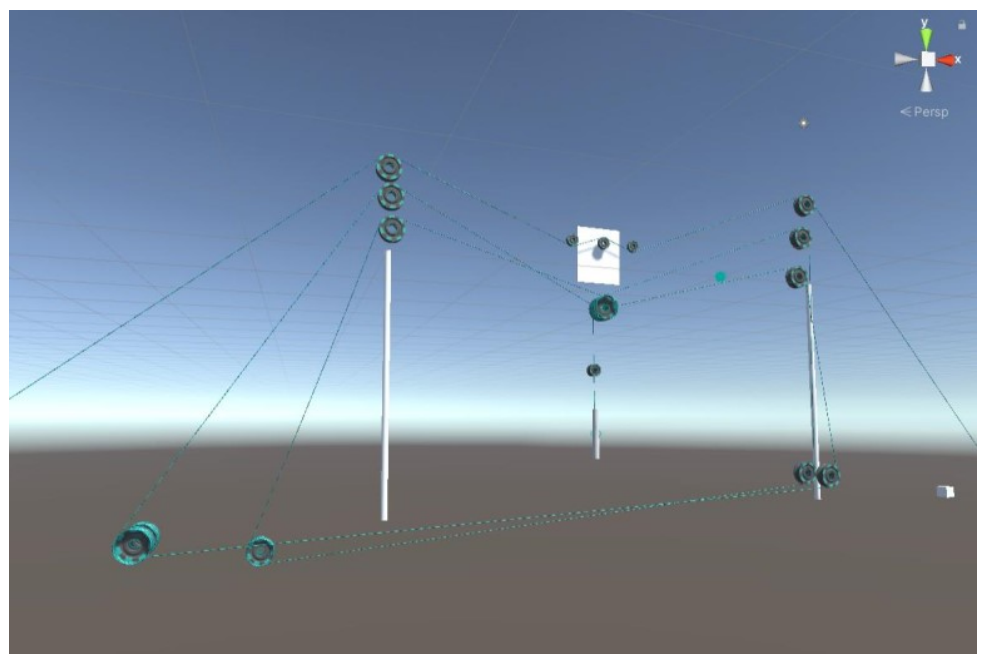

Figure 9. Double Endless system.

\section{Impose Cable System onto Field Terrain}

We over place a cable system onto field terrain, Figure 9, which undergoes design evaluation at the planning site. 


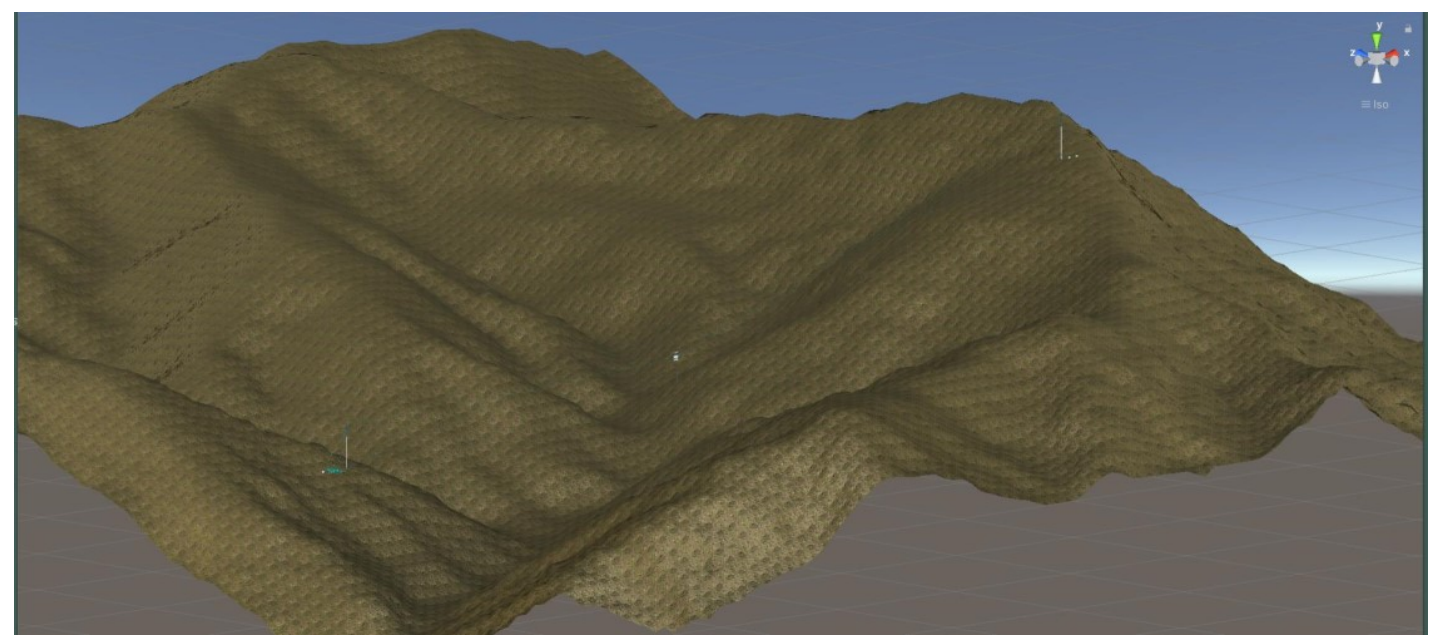

Figure 10. A cable yarding skyline system over paced onto field terrain.

It requires scale adjusting between cable system and terrain. It also favorable to equip an adequate user interface for easy cable drum activation.

\section{Cable Operation movement Simulation}

Yarding operation simulation can be conducted by activating operating line drums, Figure 11. Each drum is rotate forward or reverse individually by keyboard tapping. A set of action can be integrated to one instruction and joystick control would be equipped, simulating actual yarder operation.

Yarding operation simulation showed almost same cycle time for yarding operation when parameters for cable crane adequate, around 7 to $10 \mathrm{~min}$ for one yarding operation cycle at carriage travel distance $300 \mathrm{~m}$ and $100 \mathrm{~m}$ for lateral yarding. We needed drum winding speed set to realistic value. Sometimes carriage run so fast intended to have shorter transfer time but easily came to unstable and out of control.

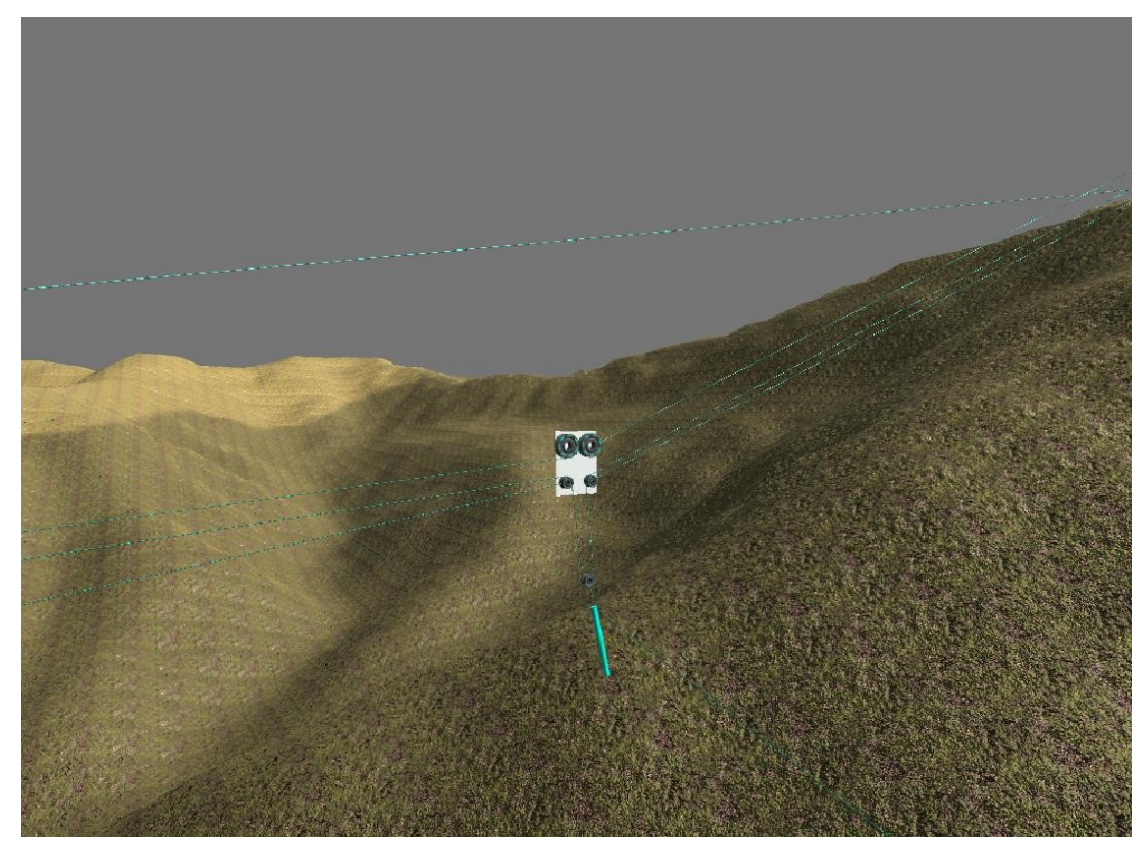

Figure 11. Yarding operation simulation. 


\section{Discussion}

This method enables discussion and feasible design on cable skyline spar trees location and operation line alignment.

From the acquisition of topographic data to the construction of cable skyline system for work simulation, it is possible to prepare in one man-day.

It would be equipped with feature packaging and an easy-to-use UI.

By collecting work operation data at the time of actual yarding operation, the results are to be stored as a data set and which would be reproduced by the 3D model, and it is possible to inherit the study evaluation and technology.

\section{Conclusion and Perspective}

Using a 3D virtual space, constructed for electrical virtual games, it is possible to study the mechanism and function of the cable yarding system with high efficiency.

It is effective for the study of the yarding operation and the technology inheritance to make the standard design of the cable yarding into a database.

The 3D virtual space modeling technology can be used to evaluate and appropriate a wide variety of forest and forestry operations, such as opening operation road, log production operation by vehicle-based machinery and variety of silvicultural operations.

This study was conducted under the 3D game development environment package Unity 3) and the wire rope system simulation was conducted under the function extension asset Filo 1)..

\section{References}

1. Filo - The Cable Simulator for Unity, https://assetstore.unity.com/packages/tools/physics/filo-the-cablesimulator-133620?locale=ja-JP, (2020/10/17) .

2. How To Make Terrain in Unity 2020, https://youtu.be/YdVUlQO2V5A, (2020/10/17).

3. Unity, https://unity.com/ja, (2020/10/17)

4. Yarding Cable Skyline Technical Textbook, Forestry and Timber Manufacturing Safety \& Health Association Japan, 2018(1966 ).

(C) 2020 by the authors. Submitted for possible open access publication under the terms and conditions of the Creative Commons Attribution (CC BY) license (http://creativecommons.org/licenses/by/4.0/). 